OPEN ACCESS

Edited by:

Guilherme Mariz de Oliveira Barra, Federal University of Santa Catarina,

Brazil

Reviewed by:

John George Hardy,

Lancaster University, United Kingdom

Walter Caseri,

ETH Zürich, Switzerland

*Correspondence:

Susana I. Córdoba de Torresi storresi@iq.usp.br

Specialty section:

This article was submitted to Polymeric and Composite Materials,

a section of the journal

Frontiers in Materials

Received: 08 February 2019

Accepted: 17 April 2019

Published: 08 May 2019

Citation:

da Silva AC and Córdoba de Torresi SI (2019) Advances in Conducting, Biodegradable and Biocompatible

Copolymers for Biomedical Applications. Front. Mater. 6:98. doi: 10.3389/fmats.2019.00098

\section{Advances in Conducting, Biodegradable and Biocompatible Copolymers for Biomedical Applications}

\author{
Aruã C. da Silva and Susana I. Córdoba de Torresi* \\ Instituto de Química, Universidade de São Paulo, São Paulo, Brazil
}

Electroactive biomaterials are a new generation of "smart" biomaterials based on intrinsically conducting polymers (ICP). Among them, poly(3,4-ethylenedioxythiophene) (PEDOT), polypyrrole (PPy) and polyaniline (PANI) are well known conducting polymers that present excellent electrical and optical properties emerging as main candidates for potential biomedical applications. Additionally, the biodegradability of biomaterials is very useful and desirable. In this context, biodegradable polymers based on polyesters, such as poly(D,L-lactic acid) (PDLLA), polycaprolactone (PCL), and poly(glycolic acid) (PGA) appear to be promising candidates because of their good biocompatibility and, as a consequence, they have been attracting attention as sustainable alternatives for applications in medicine. Weak molecular interaction with cells, biocompatibility, biodegradability, mechanics and topography are some of the main challenges for the use of conducting polymers as biomaterials. In order to improve their own biocompatibility, the main strategies are whether by doping with specific counter ions (biodopants) or chemically modifying the monomers with different molecules. Although conventional ICPS still present low or none biodegradability, there are relatively few examples of biodegradable electroactive polymers in the literature. Recently, novel approaches have been applied to solve the problem of lack of biodegradability of conducting polymers, mainly through (1) synthesis of a modified electroactive oligomers connected via degradable ester linkages creating block copolymers and (2) synthesis of modified electroactive and biodegradable macromonomers based on polyesters used in a second step copolymerization with conductive monomers. This mini-review focuses on developing trends, challenges and summarizes the recent advances on synthesis of conducting, biodegradable and biocompatible copolymers in terms of optimizing the chemical properties to improved response toward different cells, aiming biomedical applications.

Keywords: biodegradation, conducting copolymers, biomaterials, biocompatible, electroactive macromonomers 


\section{INTRODUCTION}

Electrically active and/or responsive tissues includes skeletal muscle, brain, and heart and had been widely explored by interfacing metallic or semi-conductor electrodes to provide electrical stimulation (Tehovnik, 1996; Merrill et al., 2005). This effect plays important role in the cellular division, development, migration, signaling, muscle contraction and would healing, for electroresponsive cell types such as myoblasts, fibroblasts, osteoblasts, chick embryo dorsal root ganglia, and neural crest cells, therefore attracts attention on tissue engineering and regenerative medicine (Tandon et al., 2009; Ghasemi-Mobarakeh et al., 2011).

Intrinsically conducting polymers (ICPs) are already demonstrated suitable for substitution of traditional electrodes based on conductors or semi-conductors (e.g., gold, platinum or glassy carbon) in biological applications due to their soft interface and electrical properties (Owens and Malliaras, 2010). Among them poly-3,4-ethylenedioxythiophene (PEDOT), polypyrrole (PPy), and polyaniline (PANI) are well known conducting polymers that present excellent electrical and optical properties (Skotheim and Reynolds, 2007).

Biodegradable materials are present in a lot of different areas, such as agriculture, medicine, packaging (storage), food, among others (Lendlein and Sisson, 2011). The biodegradable properties are usually present in polymeric materials by the loss of bulk weight through the polymer chain breaking into small pieces by enzymes, living organisms, environmental conditions or simply by water molecules (Siracusa et al., 2008; Vroman and Tighzert, 2009; Lendlein and Sisson, 2011). For biomedical applications, biodegradability is highly desirable for devices which perform their function and automatically "disappear" from the body, either reabsorbed or eliminated (Ulery et al., 2011). For this purpose, the degradation products must be biocompatible with biological systems; so, they are obtained by monomers commonly present in the body. Among them, polyesters appear as good candidates and have been extensively applied as biomaterials (Nair and Laurencin, 2007). Nonetheless, polyglycolide (PGA) (Mooney et al., 1996; Moutos et al., 2007), polylactides (PLA, PLLA or PDLLA) (Yang et al., 2005a,b; Lasprilla et al., 2012; Shi et al., 2016) and polycaprolactones (PCL) (Kweon et al., 2003; Ghasemi-Mobarakeh et al., 2008) have been the most investigated due to the ease obtaining and good mechanical properties.

Recently, a new class has emerged as potential candidates on biomedical field, the biodegradable electrically conducting polymers (BECP), which allies enough conductivity (i.e., allow electrical stimulation) with biodegradable properties (Rivers et al., 2002). Nowadays, a huge number of applications require biomaterials which can interface with cells, tissues or biomolecules. The molecular events at the biointerface usually involves a complex matrix with water molecules, proteins, and ions (Kasemo and Lausmaa, 1994; Ploux et al., 2010; Timko et al., 2010). In this context, proteins can regulate the cell fate, even inside cells (regulated by genes expressions) or those secreted from cells in the extracellular matrix (ECM). This plays an important role in the interaction with biomaterials once their orientation and conformation supposed to be fundamental for biocompatibility (Stevens and George, 2005). To understand how the ICP/cell biointerface works, several studies have investigated the role of adsorbed ECM proteins, among them fibronectin (FN), laminin and fibrinogen, for supporting cell adhesion, migration, proliferation, differentiation, and other processes (Rief et al., 2000; Kotwal and Schmidt, 2001; Oberhauser et al., 2002; Kandel et al., 2014). Some important properties have been found to play an important role, such as protein conformation, surface charges, different dopants or oxidized/reduced state of ICP (Svennersten et al., 2009; Gelmi et al., 2010, 2013a,b; Nelea and Kaartinen, 2010; Persson et al., 2011).

In this context, the present mini-review focus on developing trends and challenges discussing the recent advances on: (1) synthesis of a modified electroactive oligomers connected via degradable ester linkages creating block copolymers (Figure 1A) and (2) synthesis of modified electroactive and biodegradable macromonomers based on polyesters used in a second step of copolymerization with conductive monomers (Figure 1B) for conducting and biodegradable biomaterials with suitable interfacial properties for biomedical applications.

\section{ELECTROACTIVE AND BIODEGRADABLE OLIGOMERS FOR BLOCK COPOLYMERS}

In the mid-1970s, Heeger et al. demonstrated that polyacetylene $(\mathrm{CH})_{\mathrm{x}}$ could turns into highly conductive when doped with iodine (Shirakawa et al., 1977), which led the authors to win the Nobel Prize in chemistry in 2000. For the next decades several studies of polymeric films with metallic and semiconducting properties had been reported (Street and Clarke, 1981). They established the important role of linear $\pi$-conjugated systems on electronic properties and conjugated polymers have emerged as the best prototypes for the linear $\pi$-conjugated systems, such as polypyrrole and polythiophenes (Roncali, 1997). In this context, some well-defined oligomer synthesis based on pyrrole were developed in order to control the synthesis and the $\pi$ conjugated system. Groenendaal and colleagues were able to obtain controlled conditions for oligo(pyrrole-2,5-diyl) from 2 to 18 units (Groenendaal et al., 1995). In 1995 and 1997, Miller et al. (Hong and Miller, 1995) and Leclerc et al. (DonatBouillud et al., 1997), respectively, proposed the synthesis of $\pi$-conjugated oligomers based on thiophene groups linked to polyesters. Then, in 2002, Langer et al. (Zelikin et al., 2002) proposed, for biomedical purposes, the synthesis of carboxylic acid functionalized pyrrole monomers obtaining a functionalized polypyrrole named as "erodible conducting polymer," based on ionizable and/or hydrolysable groups that could promote its partial water solubilization. The carboxylic acid functionalized polypyrroles were not able to break the conjugated chain but partially solubilize it; therefore, the correct term should be a partially biodegradable conducting polymer.

With this purpose in mind, Schmidt et al. (Rivers et al., 2002) based on the idea of electrical properties of thiophenes and knowing that three pyrrole rings were enough to achieve $\pi$-conjugation, they were the first to demonstrate, by using modification of previous synthesis of $\pi$-conjugated oligomers 


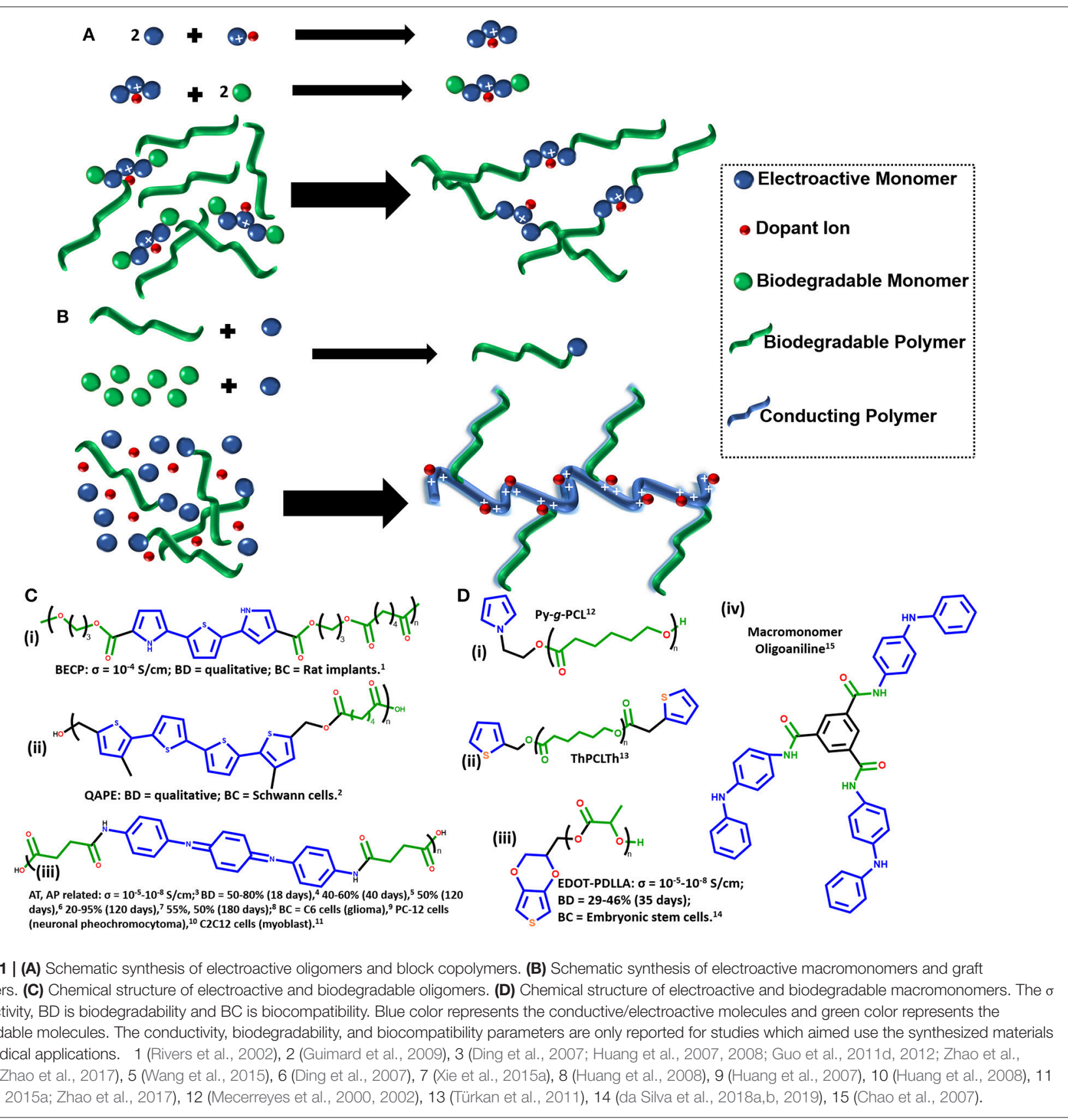

(Hong and Miller, 1995; Donat-Bouillud et al., 1997), the feasibility of creating the first BECP (Figure 1Ci) by using ester linkages (PLA) to achieve biodegradability and electrical conductivity based on three $\pi$-conjugated rings, a thiophene with two other pyrroles (Rivers et al., 2002). It was necessary to add a thiophene group in order to improve stability to the oligomer during synthesis (Rivers et al., 2002). Additionally, previous studies on macrophages activity using polyethylene revealed an important role of size and dose dependency, evidencing that small particles $(0.24 \mu \mathrm{m})$ stimulated macrophages activity (Green et al., 2000; Ingram et al., 2004). Thus, Schmidt et al. (Rivers et al., 2002) assumed that the conducting oligomers could be easily removed via macrophages. However, the material was only possible to be doped with iodine vapor which could increase cytotoxicity. Trying to solve this problem, several years later the same group proposed the synthesis of 5,5"' -bis(hydroxymethyl)-3, $3^{\prime \prime \prime}$-dimethyl$2,2^{\prime}: 5^{\prime}, 2^{\prime}: 5^{\prime \prime}, 2^{\prime \prime \prime}$ - quaterthiophene-co-adipic acid polyester (QAPE) (Figure 1Cii) as an electroactive oligothiophene unit (block of four thiophenes) with in vitro cytocompatibility studies for Schwann cells attested a non-cytotoxicity property (Guimard et al., 2009). Recently, Schmidt et al. (Hardy et al., 2014, 2015) reported electrochemically triggered biodegradable electroactive polymer oligoaniline-based materials for drug delivery.

Another remarkable synthesis of BECP was proposed by Wei et al. (Huang et al., 2007) in 2007, changing the electroactive 
oligomer for an aniline pentamer (AP) (Figure 1Ciii) through ester linkages (based on PLA again) in a triblock copolymer called "PLA- $b$-AP- $b$-PLA." However, due to a molecular weight of $\sim 10 \mathrm{kDa}$, it did not present enough mechanical and plasticity properties for their practical applications. Thus, in the next year the same group proposed an improvement to the final properties of the biomaterial by adding multiblocks of PLA $\left(M_{W}\right.$ $=2.16 \mathrm{kDa})$ to get a higher molecular weight $\left(\mathrm{M}_{\mathrm{w}}=89.8\right.$ $\mathrm{kDa}$ ) to the copolymer. Furthermore, it attended good solubility, mechanical properties and ease the processability, also keeping its own electroactivity, biodegradability and biocompatibility with in vitro experiments tested for PC-12 cells (Huang et al., 2008). Nonetheless, the cytotoxicity for the degradation products demonstrated in this study, where the aniline oligomers (AP) exhibited low cell viability for rat C6 cell line when compared to PLA and PLAAP, being ideal to use a low content of aniline oligomers(Huang et al., 2008). In parallel, Zhang et al. (Ding et al., 2007) proposed the polycondensation between carboxyl-capped aniline pentamer (CCAP) and hydroxyl-capped polyglycolide (PGA) by using $\mathrm{N}, \mathrm{N}^{\prime}$-dicyclohexylcarbodiimide (DCC) as coupling reagent and tested its degradability $(\sim 50 \%$ after 120 days) and electroactivity, but no cell experiments were performed.

In 2010, Albertsson et al. (Guo et al., 2010a) proposed the incorporation of amino-capped aniline trimer (ACAT), previously proposed by different research groups (Wei et al., 1996; Wang et al., 1998; Lu et al., 1999) and also the use of CCAP, both bonding to PLLA biodegradable chains but focused in different architectures of the biomaterials by using branched PLLAs. Then, the same group proposed the copolymerization of CCAP with linear and branched PCLs, obtained as a final product a linear and two different hyperbranched copolymers, also called "star-shape architecture" by themselves (Guo et al., 2010b). Later, poly(ethylene glycol) (PEG) was incorporated to the synthetic route in order to create hydrogels with conductive and biodegradable properties, based on acrylated PDLLA-PEGPDLLA and aniline tetramer (AT), (Guo et al., 2011a) PCLPEG-PCL with CCAP, (Guo et al., 2011b) and to improve the nondegradability of CS-graft-PANI hydrogels (Marcasuzaa et al., 2010) a CS-graft-AT was proposed by the same group (Guo et al., 2011c). After all the experience on synthesis with aniline oligomers and polyesters, the same group proposed a "universal two-step approach" for the synthesis of block copolymers oligoaniline-based, by using aniline dimer (AD) to obtain AT (Guo et al., 2011d). Then, by using the same approach, the size-tunable nanoparticles from the self-assembly coil-rod-coil triblock copolymers (Guo et al., 2011e) and the functionalization of PLA surface with AT to improve hydrophilicity were proposed (Guo et al., 2012).

In 2015, Ma et al. (Xie et al., 2015a) designed an electroactive degradable shape memory polymer network based on starshaped, produced with PLA and ACAT as previously mentioned (Guo et al., 2010b), but now demonstrated their potential application for bone tissue engineering. Once conductive elastomers have been rarely reported in literature, the same group designed an AT-based electroconductive elastomer, which is a class of materials that mimic the mechanical properties of some specific tissues (Chen et al., 2015a) Their proposal led to high stretchability and low modulus material trying to simulate soft human tissues by using AT as rigid block, PEG and PLLA as soft ones. They investigated the molecular weight of PEG ( 1 to $6 \mathrm{kDa}$ ), amount of AT in the synthesis $(3,6$, or $12 \% \mathrm{wt}$ ) and added end groups either cross-linked with trimethylolpropane (branched) or terminated with $n$-propanol (linear) (Chen et al., 2015a). Later, they designed a series of novel biocompatible biodegradable and electroactive polyurethaneurea (PUU) copolymers by combining the elastomeric property of polyurethane, conductive property of oligoaniline and the general good biodegradability and biocompatibility of PLLA (Chen et al., 2015b). Furthermore, it was investigated the effect of different molecular weight of PLLA (1500, 3500, or $8000 \mathrm{Da})$ on the final properties of the biomaterial (Chen et al., 2015b). Similar aniline oligomer-based biomaterials had been applied by the same research group for a wide range of applications, such as enhancement of myogenic differentiation of $\mathrm{C} 2 \mathrm{C} 12$ myoblast cells, (Chen et al., 2015b; Wang et al., 2015; Xie et al., 2015a,b; Deng et al., 2016; Zhao et al., 2017) improve osteogenic differentiation from bone marrow derived mesenchymal stem cells (Li et al., 2016) and enhance myelin gene expression and neurotrophin secretion of Schwann cells (Wu et al., 2016).

Recently in the field of biomedical applications, Ma and colleagues had been substituting the conductive part of biomaterials for carbon nanotubes, avoiding aniline-based ones (Wu et al., 2017). It was already demonstrated that the conductivity of PANI and PANI-based material is strongly dependent on protonation (Cao et al., 1995; Stejskal et al., 2004). For biomedical applications, it supposed to have a deleterious effect when exposed to cells for a long period, either for biocompatibility or electrical stability (Meng et al., 2008; Green et al., 2012; Mawad et al., 2016). At this point, in 2017 Stevens et al. (Spicer et al., 2017) proposed a series of conjugated oligomers of EDOT as an interesting alternative to oligoanilines for tissue engineering.

\section{ELECTROACTIVE AND BIODEGRADABLE MACROMONOMERS FOR GRAFT COPOLYMERS}

Electroactive macromonomers can be defined as a reactive macromolecule which can be further electrochemically or chemically polymerized, due to electroactive functionalities on the chain, in order to obtain a copolymer. It is possible to copolymerize it with the same macromonomers, achieving "block copolymers structure," or by adding other individual monomers, grafting the macromonomer to other homopolymer chain, called "graft copolymers" (Figure 1B) (Yagci and Toppare, 2003).

Electroactive macromonomers are a very useful way to add new properties or functionalities to prepare block or graft copolymers. Usually the homopolymer presents completely different characteristics when compared to the copolymer. In this way, part of the interesting properties desired when adding electroactive macromonomers could be improved solubility, processability, biocompatibility, biodegradability, 

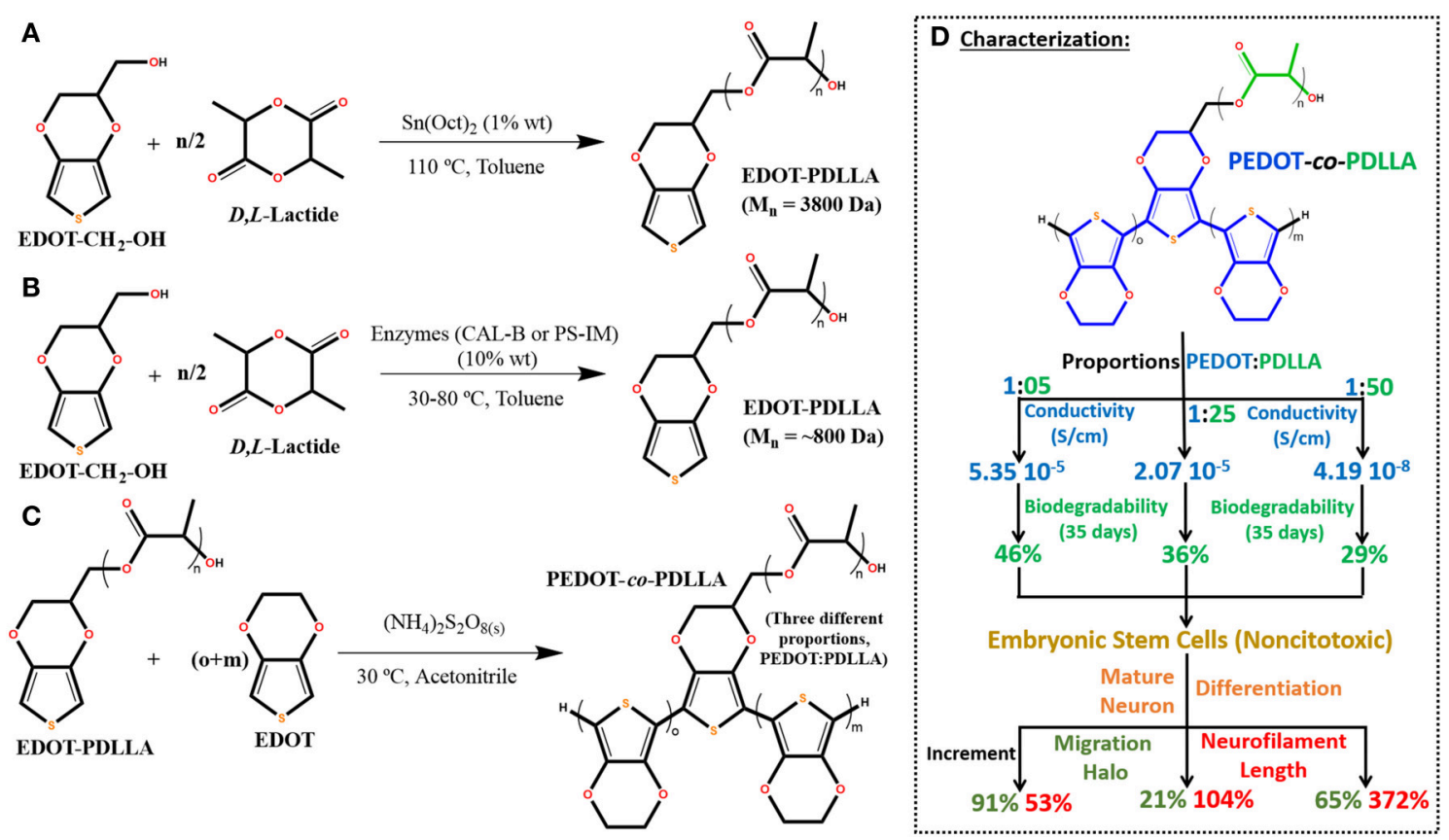

FIGURE 2 | Reactions of obtaining electroactive macromonomer of EDOT-PDLLA (A) via organometallic catalyst, (B) via enzymatic pathway and (C) "grafting through" copolymerization of PEDOT-co-PDLLA. (D) Summary of characterized properties for 1:05, 1:25, and 1:50 ratios (PEDOT:PDLLA) (da Silva et al., 2018a,b, 2019).

etc. However, it supposed to be aware that some functionalities on macromonomers can affect the $\pi$-electron density on conjugated backbone. It could either create a very stable conjugation which cannot be electropolymerized anymore or destabilize the macromonomer to degrade or promote side reactions instead the desired copolymer. An example of this is the addition of a oxadiazole group to oligothiophene chain, which are electron-withdrawing group, leading the thiophene trimers to do not electropolymerize and to promote an oxidative side reaction at high potentials that destroys the copolymer, whereas the thiophene pentamers can be electropolymerized (Fisyuk et al., 2005).

Toppare and Yagci have extensively worked with the "grafting through" method applied for electroactive macromonomers, mainly based on pyrrole and thiophene (Yagci and Toppare, 2003). Their approach was used to obtain ICPs with improved processability and mechanical properties, but focused on biosensing applications (Alkan et al., 1999; Kizilyar et al., 1999; Cirpan et al., 2001; Yagci and Toppare, 2003; Arica et al., 2005; Sahin et al., 2005; Uygun et al., 2010). There are a vast literature and excellent reviews on the grafting polymer chains for biointerfaces (Hackett et al., 2017), macromonomer techniques (Ito, 1998; Adachi and Tsukahara, 2015), functional materials (Strover et al., 2016), electroactive materials (Pron et al., 2010), biodegradable and electrically conducting polymers (Guo et al., 2013) and biomimetic conducting polymers (Hardy et al., 2013).

In 2000, Grande et al. (Mecerreyes et al., 2000) proposed the synthesis of novel pyrrole end-functional macromonomers prepared by ring-opening polymerization with $\varepsilon$-caprolactone (Py-g-PCL) (Figure 1Di). The aim of the work was not targeting the use for biomedical applications, but showed its versatility on copolymerizing with different polymers to change its final properties (Mecerreyes et al., 2002). In 2004, Catellani et al. (Dall'Acqua et al., 2004) proposed a intrinsically conductive cellulose-polypyrrole textile which they speculated could be useful from clothing to biomedical applications.

Recently, some of these graft copolymers based on electroactive macromonomer approach have been effectively proposed for biomedical field, mainly based on pyrrole (Domagala et al., 2014; Guo et al., 2017) aniline (Figure 1Div) (Chao et al., 2007; Peng et al., 2011) or thiophene groups,(Türkan et al., 2011) but most works are using the electroactive aniline-based oligomers previously discussed in this minireview. Although some research groups propose new synthetic routes for novel copolymers and characterize the physical chemistry properties which could be useful in biomedical applications, studies of biocompatibility are not commonplace.

Regarding some of this issues, in 2018 our group proposed the synthesis for a novel electroactive macromonomer based on PDLLA with 3,4-ethylenedioxythiophene (EDOT) functionalized end group (Figure 1Diii) (da Silva et al., 2018a). Aiming biomedical applications, the proposed synthesis was performed either by using an organometallic catalyst (traditional method, with stannous octanoate) (Figure 2A) or by enzymatic pathway (two different lipases, CAL-B or PS-IM) (Figure 2B) to promote ring-opening polymerization of PLA. The organometallic catalyst builds up an electroactive macromonomer three times longer than the enzymatic ones. 
Ozdemir et al. (Türkan et al., 2011) proposed a similar electroactive macromonomer with PCL and thiophenecapped (ThPCLTh) (Figure 1Dii) and reported the thiophene end groups could not react and polymerize. Thus, they copolymerized it with other conducting polymers (pyrrole and thiophene monomers) and no further cell experiments were performed to investigate the biocompatibility. Our study showed that the electroactive macromonomer of EDOT-PDLLA was able to electropolymerize at the same electrical potential of EDOT monomers, but no film formation was observed due to the soluble nature of EDOT-PDLLA in organic solvents, being able to produce only some non-conductive soluble oligomers (da Silva et al., 2018a).

Based on previous observations, we proposed by "grafting through" the electroactive macromonomer approach to synthesize copolymers of PEDOT-coPDLLA in three different proportions $(1: 05,1: 25$, and 1:50) (Figures 2C,D), leading to completely different final properties. The conductivity and biodegradability were characterized and noncytotoxic properties toward embryonic stem cells (Figure 2D) were found. Additionally, the copolymers presented an unexpected differentiation of the embryonic stem cells to mature neurons with migration halos and neurofilament lengths increased up to 65 and $370 \%$, respectively, when compared to control (da Silva et al., 2018b).

In order to understand the different copolymer compositions, the nanoscale electrical properties of the films and the interaction with FN were characterized. It was observed that 1:50 copolymer films produced more uniform current dispersion (by Conductive-AFM) and the interface with different surface potential (negative interface, by Kelvin Probe Force Measurement) when compared to other copolymers. We speculate that it was related to a more homogeneously dispersed anionic doping on 1:50 during synthesis and film production. That nature of biointerface characteristics supposed to contribute for a higher FN affinity and stronger adsorption, 5 and 3 times stronger than for 1:05 and 1:25, respectively (da Silva et al., 2019).

\section{REFERENCES}

Adachi, K., and Tsukahara, Y. (2015). Encyclopedia of Polymeric Nanomaterials. Heidelberg: Springer, 1167-1175.

Alkan, S., Toppare, L., Hepuzer, Y., and Yagci, Y. (1999). Block copolymers of thiophene-capped poly(methyl methacrylate) with pyrrole. J. Polym. Sci. Part A Polym. Chem. 37, 4218-4225. doi: 10.1002/(SICI)10990518(19991115)37:22<4218::AID-POLA22>3.0.CO;2-Z

Arica, M. Y., Bayramoglu, G., Arica, B., Yalçin, E., Ito, K., and Yagci, Y. (2005). Novel hydrogel membrane based on copoly(hydroxyethyl methacrylate/p-vinylbenzyl-poly(ethylene oxide)) for biomedical applications: properties and drug release characteristics. Macromol. Biosci. 5, 983-992. doi: 10.1002/mabi.2005 00091

Cao, Y., Qiu, J., and Smith, P. (1995). Effect of solvents and co-solvents on the processibility of polyaniline: I. solubility and conductivity studies. Synth. Met. 69, 187-190. doi: 10.1016/0379-6779(94)0 2412-R

\section{CONCLUDING REMARKS AND OUTLOOK}

Electroactive aniline-based oligomers have been extensively studied, and their toxicity is a limiting factor for biomedical applications. Proposals of new electroactive oligomers based on more stable and biocompatible electroactive monomers and/or oligomers may be interesting in this field. Additionally, another alternative may be the use of very low aniline-based oligomers content or to create new strategies to increase the biocompatibility.

The electroactive macromonomers emerge as a useful tool to obtain graft copolymers with conductivity and biodegradability properties. However, more studies are still necessary to apply that kind of biomaterials on cellular experiments, such as tissue engineering, biomedical devices, scaffold/templates, etc. It would provide great insights for the development of this area.

Another important remark is related to the fact that not only the synthesis of new materials is worth but also to go deeper in their characterization. Recently, important studies have been specifically looking to the biointerface of the materials with cells, whether by studying nanoscale properties or interactions with biomolecules, trying to understand what should be better for cell interfacing. Finally, the knowledge would lead us for smarter biomaterial designing in the future.

\section{AUTHOR CONTRIBUTIONS}

All authors listed have made a substantial, direct and intellectual contribution to the work, and approved it for publication.

\section{ACKNOWLEDGMENTS}

We gratefully acknowledge Brazilian agencies (São Paulo Research Foundation FAPESP, Proc. 2015/26308-7 and 2018/13492-2; the National Council for Scientific and Technological Development, $\mathrm{CNPq}$; and Coordination of Improvement of Higher Level Personnel, CAPES) for their financial support. ACdS thanks FAPESP (Proc. 2014/09353-6, 2017/00705-5) for scholarships.

Chao, D., Ma, X., Lu, X., Cui, L., Mao, H., Zhang, W., et al. (2007). Electroactive hyperbranched polyamide synthesized by oxidative coupling polymerization within an A2 + B3 Strategy. Macromol. Chem. Phys. 208, 658-664. doi: 10.1002/macp.200600571

Chen, J., Dong, R., Ge, J., Guo, B., and Ma, P. X. (2015b). Biocompatible, biodegradable, and electroactive polyurethane-urea elastomers with tunable hydrophilicity for skeletal muscle tissue engineering. ACS Appl. Mater. Interfaces 7, 28273-28285. doi: 10.1021/acsami.5b10829

Chen, J., Guo, B., Eyster, T. W., and Ma, P. X. (2015a). Super stretchable electroactive elastomer formation driven by aniline trimer self-assembly. Chem. Mater. 27, 5668-5677. doi: 10.1021/acs.chemmater.5b02086

Cirpan, A., Alkan, S., Toppare, L., David, G., and Yagci, Y. (2001). Synthesis and electroactivity of pyrrole end-functionalized poly(2-methyl-2-oxazoline). Eur. Polym. J. 37, 2225-2229. doi: 10.1016/S0014-3057(01)00103-3

da Silva, A. C., Augusto, T., Andrade, L. H., and Córdoba de Torresi, S. I. (2018a). One pot biocatalytic synthesis of a biodegradable electroactive macromonomer based on 3,4-ethylenedioxytiophene and poly( 1 -lactic acid). Mater. Sci. Eng. C 83, 35-43. doi: 10.1016/j.msec.2017.09.007 
da Silva, A. C., Higgins, M. J., and Córdoba de Torresi, S. I. (2019). The effect of nanoscale surface electrical properties of partially biodegradable PEDOT-coPDLLA conducting polymers on protein adhesion investigated by atomic force microscopy. Mater. Sci. Eng. C. 99, 468-478. doi: 10.1016/j.msec.2019.01.103

da Silva, A. C., Semeano, A. T. S., Dourado, A. H. B., Ulrich, H., and Cordoba de Torresi, S. I. (2018b). Novel conducting and biodegradable copolymers with noncytotoxic properties toward embryonic stem cells. ACS Omega 3, 5593-5604. doi: 10.1021/acsomega.8b00510

Dall'Acqua, L., Tonin, C., Peila, R., Ferrero, F., and Catellani, M. (2004). Performances and properties of intrinsic conductive cellulose-polypyrrole textiles. Synth. Met. 146, 213-221. doi: 10.1016/j.synthmet.2004.07.005

Deng, Z., Guo, Y., Zhao, X., Li, L., Dong, R., Guo, B., et al. (2016). Stretchable degradable and electroactive shape memory copolymers with tunable recovery temperature enhance myogenic differentiation. Acta Biomater. 46, 234-244. doi: 10.1016/j.actbio.2016.09.019

Ding, C., Wang, Y., and Zhang, S. (2007). Synthesis and characterization of degradable electrically conducting copolymer of aniline pentamer and polyglycolide. Eur. Polym. J. 43, 4244-4252. doi: 10.1016/j.eurpolymj.2007.07.032

Domagala, A., Maksymiak, M., Janeczek, H., Musiol, M., Turczyn, R., Ledwon, P., et al. (2014). Oligo-3-hydroxybutyrate functionalised pyrroles for preparation of biodegradable conductive polymers. J. Mater. Sci. 49, 5227-5236. doi: 10.1007/s10853-014-8241-0

Donat-Bouillud, A., Mazerolle, L., Gagnon, P., Goldenberg, L., Petty, M. C., and Leclerc, M. (1997). Synthesis, characterization, and processing of new electroactive and photoactive polyesters derived from oligothiophenes. Chem. Mater. 9, 2815-2821. doi: 10.1021/cm9701926

Fisyuk, A. S., Demadrille, R., Querner, C., Zagorska, M., Bleusec, J., and Pron, A. (2005). Mixed alkylthiophene-based heterocyclic polymers containing oxadiazole units via electrochemical polymerisation: spectroscopic, electrochemical and spectroelectrochemical properties. New J. Chem. 29:707. doi: $10.1039 / \mathrm{b} 415587 \mathrm{~d}$

Gelmi, A., Higgins, M. J., and Wallace, G. G. (2010). Physical surface and electromechanical properties of doped polypyrrole biomaterials. Biomaterials 31, 1974-1983. doi: 10.1016/j.biomaterials.2009.11.040

Gelmi, A., Higgins, M. J., and Wallace, G. G. (2013a). Quantifying fibronectin adhesion with nanoscale spatial resolution on glycosaminoglycan doped polypyrrole using atomic force microscopy. Biochim. Biophys. Acta Gen. Subj. 1830, 4305-4313. doi: 10.1016/j.bbagen.2013.03.005

Gelmi, A., Higgins, M. J., and Wallace, G. G. (2013b). Resolving sub-molecular binding and electrical switching mechanisms of single proteins at electroactive conducting polymers. Small 9, 393-401. doi: 10.1002/smll.201201686

Ghasemi-Mobarakeh, L., Prabhakaran, M. P., Morshed, M., Nasr-Esfahani, M.H., and Ramakrishna, S. (2008). Electrospun poly( $\varepsilon$-caprolactone)/gelatin nanofibrous scaffolds for nerve tissue engineering. Biomaterials 29, 4532-4539. doi: 10.1016/j.biomaterials.2008.08.007

Ghasemi-Mobarakeh, L., Prabhakaran, M. P., Morshed, M., Nasr-Esfahani, M. H., Baharvand, H., Kiani, S., et al. (2011). Application of conductive polymers, scaffolds and electrical stimulation for nerve tissue engineering. J. Tissue Eng. Regen. Med. 5, e17-e35. doi: 10.1002/term.383

Green, R. A., Hassarati, R. T., Bouchinet, L., Lee, C. S., Cheong, G. L., Yu, J. F., et al. (2012). Substrate dependent stability of conducting polymer coatings on medical electrodes. Biomaterials 33, 5875-5886. doi: 10.1016/j.biomaterials.2012.05.017

Green, T. R., Fisher, J., Matthews, J. B., Stone, M. H., and Ingham, E. (2000). Effect of size and dose on bone resorption activity of macrophages by in vitro clinically relevant ultra high molecular weight polyethylene particles. J. Biomed. Mater. Res. 53, 490-497. doi: 10.1002/1097-4636(200009)53:5<490::AID-JBM7>3.0. $\mathrm{CO} ; 2-7$

Groenendaal, L., Peerlings, H. W. I., van Dongen, J. L. J., Havinga, E. E., Vekemans, J. A. J. M., and Meijer, E. W., et al. (1995). Well-defined oligo(pyrrole-2,5-diyl)s by the ullmann reaction. Macromolecules 28, 116-123. doi: $10.1021 / \mathrm{ma} 00105 \mathrm{a} 015$

Guimard, N. K. E., Sessler, J. L., and Schmidt, C. E. (2009). Toward a biocompatible and biodegradable copolymer incorporating electroactive oligothiophene units. Macromolecules 42, 502-511. doi: 10.1021/ma8019859

Guo, B., Finne-Wistrand, A., and Albertsson, A.-C. (2010b). Enhanced electrical conductivity by macromolecular architecture: hyperbranched electroactive and degradable block copolymers based on poly( $\varepsilon$-caprolactone) and aniline pentamer. Macromolecules 43, 4472-4480. doi: 10.1021/ma100530k

Guo, B., Finne-Wistrand, A., and Albertsson, A.-C. (2011a). Degradable and electroactive hydrogels with tunable electrical conductivity and swelling behavior. Chem. Mater. 23, 1254-1262. doi: 10.1021/cm103498s

Guo, B., Finne-Wistrand, A., and Albertsson, A.-C. (2011b). Versatile functionalization of polyester hydrogels with electroactive aniline oligomers. J. Polym. Sci. Part A Polym. Chem. 49, 2097-2105. doi: 10.1002/pola.24643

Guo, B., Finne-Wistrand, A., and Albertsson, A.-C. (2011d). Universal two-step approach to degradable and electroactive block copolymers and networks from combined ring-opening polymerization and postfunctionalization via oxidative coupling reactions. Macromolecules 44, 5227-5236. doi: 10.1021/ma2009595

Guo, B., Finne-Wistrand, A., and Albertsson, A.-C. (2011e). Simple route to sizetunable degradable and electroactive nanoparticles from the self-assembly of conducting coil-rod-coil triblock copolymers. Chem. Mater. 23, 4045-4055. doi: $10.1021 / \mathrm{cm} 201782 \mathrm{v}$

Guo, B., Finne-Wistrand, A., and Albertsson, A.-C. (2012). Electroactive hydrophilic polylactide surface by covalent modification with tetraaniline. Macromolecules 45, 652-659. doi: 10.1021/ma202508h

Guo, B., Finne-Wistrand, A., and Albertsson, A. C. (2010a). Molecular architecture of electroactive and biodegradable copolymers composed of polylactide and carboxyl-capped aniline trimer. Biomacromolecules 11, 855-863. doi: $10.1021 / \mathrm{bm} 9011248$

Guo, B., Finne-Wistrand, A., and Albertsson, A. C. (2011c). Facile synthesis of degradable and electrically conductive polysaccharide hydrogels. Biomacromolecules 12, 2601-2609. doi: 10.1021/bm200389t

Guo, B., Glavas, L., and Albertsson, A.-C. (2013). Biodegradable and electrically conducting polymers for biomedical applications. Prog. Polym. Sci. 38, 1263-1286. doi: 10.1016/j.progpolymsci.2013.06.003

Guo, H., Qiao, T., Jiang, S., Li, T., Song, P., Zhang, B., et al. (2017). Aligned poly (glycolide-lactide) fiber membranes with conducting polypyrrole. Polym. Adv. Technol. 28, 484-490. doi: 10.1002/pat.3912

Hackett, A. J., Malmström, J., and Travas-Sejdic, J. (2017). Functionalization of conducting polymers for biointerface applications. Prog. Polym. Sci. 70, 18-33. doi: 10.1016/j.progpolymsci.2017.03.004

Hardy, J. G., Amend, M. N., Geissler, S., Lynch, V. M., and Schmidt, C. E. (2015). Peptide-directed assembly of functional supramolecular polymers for biomedical applications: electroactive molecular tongue-twisters (oligoalanineoligoaniline-oligoalanine) for electrochemically enhanced drug delivery. $J$. Mater. Chem. B 3, 5005-5009. doi: 10.1039/C5TB00106D

Hardy, J. G., Lee, J. Y., and Schmidt, C. E. (2013). Biomimetic conducting polymer-based tissue scaffolds. Curr. Opin. Biotechnol. 24, 847-854. doi: 10.1016/j.copbio.2013.03.011

Hardy, J. G., Mouser, D. J., Arroyo-Currás, N., Geissler, S., Chow, J. K., Nguy, L., et al. (2014). Biodegradable electroactive polymers for electrochemically-triggered drug delivery. J. Mater. Chem. B 2, 6809-6822. doi: $10.1039 /$ C4TB00355A

Hong, Y., and Miller, L. L. (1995). An electrically conducting polyester that has isolated quatrathiophene units in the main chain. Chem. Mater. 7, 1999-2000. doi: $10.1021 / \mathrm{cm} 00059 \mathrm{a} 003$

Huang, L., Hu, J., Lang, L., Wang, X., Zhang, P., Jing, X., et al. (2007) Synthesis and characterization of electroactive and biodegradable ABA block copolymer of polylactide and aniline pentamer. Biomaterials 28, 1741-1751. doi: 10.1016/j.biomaterials.2006.12.007

Huang, L., Zhuang, X., Hu, J., Lang, L., Zhang, P., Wang, Y., Huang, L., et al. (2008). Synthesis of biodegradable and electroactive multiblock polylactide and aniline pentamer copolymer for tissue engineering applications. Biomacromolecules 9 , 850-858. doi: $10.1021 / \mathrm{bm} 7011828$

Ingram, J. H., Stone, M., Fisher, J., and Ingham, E. (2004). The influence of molecular weight, crosslinking and counterface roughness on TNF-alpha production by macrophages in response to ultra high molecular weight polyethylene particles. Biomaterials 25, 3511-3522. doi: 10.1016/j.biomaterials.2003. 10.054

Ito, K. (1998). Polymeric design by macromonomer technique. Prog. Polym. Sci. 23, 581-620. doi: 10.1016/S0079-6700(97)0 0049-X 
Kandel, J., Lee, H. S., Sobolewski, P., Tomczyk, N., Composto, R. J., and Eckmann, D. M. (2014). Chemically grafted fibronectin for use in QCM-D cell studies. Biosens. Bioelectron. 58, 249-257. doi: 10.1016/j.bios.2014.02.053

Kasemo, B., and Lausmaa, J. (1994). Material-tissue interfaces: the role of surface properties and processes. Environ. Health Perspect. 102, 41-45. doi: 10.1289/ehp.94102s541

Kizilyar, N., Akbulut, U., Toppare, L., Özden, M. Y., and Yagci, Y. (1999). Immobilization of invertase in conducting polypyrrole/polytetrahydrofuran graft polymer matrices. Synth. Met. 104, 45-50. doi: 10.1016/S0379-6779(99)00033-8

Kotwal, A., and Schmidt, C. E. (2001). Electrical stimulation alters protein adsorption and nerve cell interactions with electrically conducting biomaterials. Biomaterials 22, 1055-1064. doi: 10.1016/S0142-9612(00)00344-6

Kweon, H., Yoo, M. K., Park, I. K., Kim, T. H., Lee, H. C., Lee, H. S., et al. (2003). A novel degradable polycaprolactone networks for tissue engineering. Biomaterials 24, 801-808. doi: 10.1016/S0142-9612(02)00370-8

Lasprilla, A. J., Martinez, G. A., Lunelli, B. H., Jardini, A. L., and Filho, R. M. (2012). Poly-lactic acid synthesis for application in biomedical devices - a review. Biotechnol. Adv. 30, 321-328. doi: 10.1016/j.biotechadv.2011.06.019

Lendlein, A., and Sisson, A. (2011). Handbook of Biodegradable Polymers. (Weinheim: Wiley-VCH Verlag GmbH \& Co. KGaA). doi: $10.1002 / 9783527635818$

Li, L., Yu, M., Ma, P. X., and Guo, B. (2016). Electroactive degradable copolymers enhancing osteogenic differentiation from bone marrow derived mesenchymal stem cells. J. Mater. Chem. B 4, 471-481. doi: 10.1039/C5TB01899D

Lu, W., Sheng Meng, X., and Yuan Wang, Z. (1999). Electrochemical behavior of a new electroactive polyimide derived from aniline trimer. $J$. Polym. Sci. Part A Polym. Chem. 37, 4295-4301. doi: 10.1002/(SICI)10990518(19991201)37:23<4295::AID-POLA5>3.0.CO;2-X

Marcasuzaa, P., Reynaud, S., Ehrenfeld, F., Khoukh, A., and Desbrieres, J. (2010). Chitosan- graft -polyaniline-based hydrogels: elaboration and properties. Biomacromolecules 11, 1684-1691. doi: 10.1021/bm100379z

Mawad, D., Mansfield, C., Lauto, A., Perbellini, F., Nelson, G. W., Tonkin, J., et al. (2016). A conducting polymer with enhanced electronic stability applied in cardiac models. Sci. Adv. 2:e1601007. doi: 10.1126/sciadv.1601007

Mecerreyes, D., Pomposo, J. A., Bengoetxea, M., and Grande, H. (2000). Novel pyrrole end-functional macromonomers prepared by ring-opening and atom-transfer radical polymerizations. Macromolecules 33, 5846-5849. doi: $10.1021 / \mathrm{ma} 0003046$

Mecerreyes, D., Stevensb, R., Nguyen, C., Pomposo, J. A., Bengoetxea, M., Grande, H., et al. (2002). Synthesis and characterization of polypyrrole-graft-poly $(\varepsilon-$ caprolactone) copolymers: new electrically conductive nanocomposites. Synth. Met. 126, 173-178. doi: 10.1016/S0379-6779(01)00503-3

Meng, S., Rouabhia, M., Shi, G., and Zhang, Z. (2008). Heparin dopant increases the electrical stability, cell adhesion, and growth of conducting polypyrrole/poly(L,L-lactide) composites. J. Biomed. Mater. Res. Part A 87, 332-344. doi: 10.1002/jbm.a.31735

Merrill, D. R., Bikson, M., and Jefferys, J. G. (2005). Electrical stimulation of excitable tissue: design of efficacious and safe protocols. J. Neurosci. Methods 141, 171-198. doi: 10.1016/j.jneumeth.2004.10.020

Mooney, D. J., Mazzoni, C. L., Breuer, C., McNamara, K., Hern, D., Vacanti, J. P., et al. (1996). Stabilized polyglycolic acid fibre-based tubes for tissue engineering. Biomaterials 17, 115-124. doi: 10.1016/0142-9612(96)85756-5

Moutos, F. T., Freed, L. E., and Guilak, F. (2007). A biomimetic three-dimensional woven composite scaffold for functional tissue engineering of cartilage. Nat. Mater. 6, 162-167. doi: 10.1038/nmat1822

Nair, L. S., and Laurencin, C. T. (2007). Biodegradable polymers as biomaterials. Prog. Polym. Sci. 32, 762-798. doi: 10.1016/j.progpolymsci.2007.05.017

Nelea, V., and Kaartinen, M. T. (2010). Periodic beaded-filament assembly of fibronectin on negatively charged surface. J. Struct. Biol. 170, 50-59. doi: 10.1016/j.jsb.2010.01.009

Oberhauser, A. F., Badilla-Fernandez, C., Carrion-Vazquez, M., and Fernandez, J. M. (2002). The mechanical hierarchies of fibronectin observed with singlemolecule AFM. J. Mol. Biol. 319, 433-447. doi: 10.1016/S0022-2836(02)0 0306-6

Owens, R. M., and Malliaras, G. G. (2010). Organic electronics at the interface with biology. MRS Bull. 35, 449-456. doi: 10.1557/mrs 2010.583
Peng, C.-W., Hsu, C.-H., Lin, K. H., Li, P.-G., Hsieh, M.-F., Wie, Y., et al. (2011). Electrochemical corrosion protection studies of aniline-capped aniline trimerbased electroactive polyurethane coatings. Electrochim. Acta 58, 614-620. doi: 10.1016/j.electacta.2011.10.002

Persson, K. M., Karlsson, R., Svennersten, K., Löffler, S., and Jager, E. W. (2011). Electronic control of cell detachment using a self-doped conducting polymer. Adv. Mater. 23, 4403-4408. doi: 10.1002/adma.201101724

Ploux, L., Ponche, A., and Anselme, K. (2010). Bacteria/material interfaces: role of the material and cell wall properties. J. Adhes. Sci. Technol. 24, 2165-2201. doi: 10.1163/016942410X511079

Pron, A., Gawrys, P., Zagorska, M., Djurado, D., and Demadrille, R. (2010). Electroactive materials for organic electronics: preparation strategies, structural aspects and characterization techniques. Chem. Soc. Rev. 39:2577. doi: $10.1039 / \mathrm{b} 907999 \mathrm{~h}$

Rief, M., Gautel, M., and Gaub, H. E. (2000). "Unfolding Forces of Titin and Fibronectin Domains Directly Measured by AFM," in Elastic Filaments of the Cell. Advances in Experimental Medicine and Biology, Vol. 481, eds H. L. Granzier and G. H. Pollack (Boston, MA: Springer), 129-141. doi: 10.1007/978-1-4615-4267-4_8

Rivers, T. J., Hudson, T. W., and Schmidt, C. E. (2002). Synthesis of a novel, biodegradable electrically conducting polymer for biomedical applications. Adv. Funct. Mater. 12:33. doi: 10.1002/1616-3028(20020101)12:1<33::AIDADFM33>3.0.CO;2-E

Roncali, J. (1997). Synthetic principles for bandgap control in linear $\pi$-conjugated systems. Chem. Rev. 97, 173-206. doi: 10.1021/cr950257t

Sahin, E., Camurlu, P., Toppare, L., Mercore, V. M., Cianga, I., Yag, Y., et al. (2005). Conducting copolymers of thiophene functionalized polystyrenes with thiophene. J. Electroanal. Chem. 579, 189-197. doi: 10.1016/j.jelechem.2005.01.017

Shi, K., Wang, Y. L., Qu, Y., Liao, J. F., Chu, B. Y., Zhang, H. P., Shi, K., et al (2016). Synthesis, characterization, and application of reversible PDLLAPEG-PDLLA copolymer thermogels in vitro and in vivo. Sci. Rep. 6:19077. doi: 10.1038/srep19077

Shirakawa, H., Louis, E. J., MacDiarmid, A. G., Chiang, C. K., and Heeger, A. J. (1977). Synthesis of electrically conducting organic polymers: halogen derivatives of polyacetylene, $(\mathrm{CH})$ x. J. Chem. Soc. Chem. Commun. 578-580. doi: 10.1039/c39770000578 Available online at: https://pubs.rsc.org/ en/content/articlelanding/1977/c3/c39770000578\#!divAbstract

Siracusa, V., Rocculi, P., Romani, S., and Rosa, M. D. (2008). Biodegradable polymers for food packaging: a review. Trends Food Sci. Technol. 19, 634-643. doi: $10.1016 / j . t i f s .2008 .07 .003$

Skotheim, T. A., and Reynolds, J. (2007). Handbook of Conducting Polymers, 2 Volume Set. (Boca Raton: CRC Press). doi: 10.1201/9781420043594

Spicer, C. D., Booth, M. A., Mawad, D., Armgarth, A., Nielsen, C. B., and Stevens, M. M. (2017). Synthesis of hetero-bifunctional, end-capped oligoEDOT derivatives. Chem 2, 125-138. doi: 10.1016/j.chempr.2016.12.003

Stejskal, J., Hlavatá, D., Holler, P., Trchová, M., Prokeš, J., Sapurina, I., et al. (2004). Polyaniline prepared in the presence of various acids: a conductivity study. Polym. Int. 53, 294-300. doi: 10.1002/pi.1406

Stevens, M. M., and George, J. H. (2005). Exploring and engineering the cell surface interface. Science. 310, 1135-1138. doi: 10.1126/science.1106587

Street, G. B., and Clarke, T. C. (1981). Conducting polymers: a review of recent work. IBM J. Res. Dev. 25, 51-57. doi: 10.1147/rd. 251.0051

Strover, L. T., Malmström, J., and Travas-Sejdic, J. (2016). Graft copolymers with conducting polymer backbones: a versatile route to functional materials. Chem. Rec. 16, 393-418. doi: 10.1002/tcr.201500216

Svennersten, K., Bolin, M. H., Jager, E. W., Berggren, M., Richter-Dahlfors, A., Svennersten, K., et al. (2009). Electrochemical modulation of epithelia formation using conducting polymers. Biomaterials 30, 6257-6264. doi: 10.1016/j.biomaterials.2009.07.059

Tandon, N., Cannizzaro, C., Chao, P. H., Maidhof, R., Marsano, A., Au, H. T., et al. (2009). Electrical stimulation systems for cardiac tissue engineering. Nat. Protoc. 4, 155-173. doi: 10.1038/nprot.2008.183

Tehovnik, E. J. (1996). Electrical stimulation of neural tissue to evoke behavioral responses. J. Neurosci. Methods 65, 1-17. doi: 10.1016/0165-0270(95)00131-X

Timko, B. P., Cohen-Karni, T., Qing, Q., Tian, B., and Lieber, C. M. (2010). Design and implementation of functional nanoelectronic interfaces with biomolecules, 
cells, and tissue using nanowire device arrays. IEEE Trans. Nanotechnol. 9, 269-280. doi: 10.1109/TNANO.2009.2031807

Türkan, A., Yilmaz, F., Küçük, A. Ç., and Özdemir, Y. (2011). One-pot twostep lipase-catalyzed synthesis of $\alpha, \omega$-thiophene-capped poly( $\varepsilon$-caprolactone) macromonomers and their use in electropolymerization. Polym. Bull. 67, 1483-1498. doi: 10.1007/s00289-011-0467-2

Ulery, B. D., Nair, L. S., and Laurencin, C. T. (2011). Biomedical applications of biodegradable polymers. J. Polym. Sci. Part B Polym. Phys. 49, 832-864. doi: $10.1002 /$ polb. 22259

Uygun, M., Tasdelen, M. A., and Yagci, Y. (2010). Influence of type of initiation on thiol-ene "click" chemistry. Macromol. Chem. Phys. 211, 103-110. doi: $10.1002 /$ macp. 200900442

Vroman, I., and Tighzert, L. (2009). Biodegradable polymers. Materials 2, 307-344. doi: $10.3390 / \mathrm{ma} 2020307$

Wang, L., Wu, Y., Guo, B., and Ma, P. X. (2015). Nanofiber yarn/hydrogel core-shell scaffolds mimicking native skeletal muscle tissue for guiding 3D myoblast alignment, elongation, and differentiation. ACS Nano. 9, 9167-9179. doi: 10.1021/acsnano.5b03644

Wang, Z., Y., Yang, C., Gao, J. P., Lin, J., and Meng, X. S. (1998). Electroactive polyimides derived from amino-terminated aniline trimer. Macromolecules 31 , 2702-2704. doi: 10.1021/ma971782s

Wei, Y., Yang, C., and Ding, T. (1996). A one-step method to synthesize N, $\mathrm{N}^{\prime}$ bis ( 4 '-aminophenyl)-1,4-quinonenediimine and its derivatives. Tetrahedron Lett. 37, 731-734. doi: 10.1016/0040-4039(95)02300-3

Wu, Y., Wang, L., Guo, B., and Ma, P. X. (2017). Interwoven aligned conductive nanofiber yarn/hydrogel composite scaffolds for engineered 3D cardiac anisotropy. ACS Nano. 11, 5646-5659. doi: 10.1021/acsnano.7b01062

Wu, Y., Wang, L., Guo, B., Shao, Y., and Ma, P. X. (2016). Electroactive biodegradable polyurethane significantly enhanced Schwann cells myelin gene expression and neurotrophin secretion for peripheral nerve tissue engineering. Biomaterials 87, 18-31. doi: 10.1016/j.biomaterials.2016. 02.010

Xie, M., Wang, L., Ge, J., Guo, B., and Ma, P. X. (2015a). Strong electroactive biodegradable shape memory polymer networks based on star-shaped polylactide and aniline trimer for bone tissue engineering. ACS Appl. Mater. Interfaces 7, 6772-6781. doi: 10.1021/acsami.5b00191

Xie, M., Wang, L., Guo, B., Wang, Z., Chen, Y. E., and Ma, P. X. (2015b). Ductile electroactive biodegradable hyperbranched polylactide copolymers enhancing myoblast differentiation. Biomaterials 71, 158-167. doi: $10.1016 /$ j.biomaterials.2015.08.042

Yagci, Y., and Toppare, L. (2003). Electroactive macromonomers based on pyrrole and thiophene: a versatile route to conducting block and graft polymers. Polym. Int. 52, 1573-1578. doi: 10.1002/ pi.1341

Yang, F., Murugan, R., Wang, S., and Ramakrishna, S. (2005b). Electrospinning of nano/micro scale poly(l-lactic acid) aligned fibers and their potential in neural tissue engineering. Biomaterials 26, 2603-2610. doi: 10.1016/j.biomaterials.2004. 06.051

Yang, J., Kim, D. H., Hendricks, J. L., Leach, M., Northey, R., and Martin, D. C. (2005a). Ordered surfactant-templated poly(3,4ethylenedioxythiophene) (PEDOT) conducting polymer on microfabricated neural probes. Acta Biomater. 1, 125-136. doi: 10.1016/j.actbio.2004. 09.006

Zelikin, A. N., Lynn, D. M., Farhadi, J., Martin, I., Shastri, V., and Langer, R. (2002). Erodible conducting polymers for potential biomedical applications. Angew. Chemie Int. Ed. 41, 141-144. doi: 10.1002/15213773(20020104)41:1<141::AID-ANIE141>3.0.CO;2-V

Zhao, X., Dong, R., Guo, B., and Ma, P. X. (2017). Dopamineincorporated dual bioactive electroactive shape memory polyurethane elastomers with physiological shape recovery temperature, high stretchability, and enhanced c2c12 myogenic differentiation. ACS Appl. Mater. Interfaces 9, 29595-29611. doi: 10.1021/acsami.7b 10583

Conflict of Interest Statement: The authors declare that the research was conducted in the absence of any commercial or financial relationships that could be construed as a potential conflict of interest.

Copyright (c) 2019 da Silva and Córdoba de Torresi. This is an open-access article distributed under the terms of the Creative Commons Attribution License (CC BY). The use, distribution or reproduction in other forums is permitted, provided the original author(s) and the copyright owner(s) are credited and that the original publication in this journal is cited, in accordance with accepted academic practice. No use, distribution or reproduction is permitted which does not comply with these terms. 